\title{
PENERAPAN TATA KELOLA SYARIAH LEMBAGA KEUANGAN ISLAM (STUDI KASUS PADA PT. BPRS JABAL NUR SURABAYA)')
}

\author{
Fachruddin 'Aabid \\ Program Studi S1 Ekonomi Islam-Fakultas Ekonomi dan Bisnis-Universitas Airlangga \\ Email: aabidfachruddin@gmail.com \\ Noven Suprayogi \\ Departemen Ekonomi Syariah-Fakultas Ekonomi dan Bisnis-Universitas Airlangga \\ Email: noven.suprayogi@feb.unair.ac.id
}

\begin{abstract}
:
This research aims to analyze the implementation process of good sharia governance (GSG) in order to ensure sharia compliance. Sharia governance is a qualitative disclosure that includes arrangements, systems, and control to ensure sharia compliance. The method using descriptive qualitative approach with case study strategy at PT. Bank Pembiayaan Rakyat Syariah (BPRS) Jabal Nur Surabaya. Data collected by in depth interview and documentation. Validation techniques using source and technic triangulation. Analysis techniques using Miles and Huberman's.

Result of this research is based on seven patterns from the sharia governance process which represents the instrumental function of the sharia supervisory board as part of the internal governance structure of corporate governance in Islamic Financial Institutions. Based on the analysis that has been conducted by researchers, PT. Bank Pembiayaan Rakyat Syariah Jabal Nur has been quite obedient in fulfillment guarantee of sharia compliance based on the implementation process of good sharia governance.
\end{abstract}

Keywords: Good Sharia Governance, Sharia Supervisory Board, Sharia Governance Process, and Sharia Compliance.

\section{PENDAHULUAN}

lqbal dan Mirakhor (2008:373)

mengungkapkan bahwa selama

beberapa dekade terakhir,

perkembangan keuangan Islam

menunjukkan perubahan dan dinamika dramatis yang cepat. Sebagai bagian instrumen pengembang aktivitas di bidang ekonomi, beragam tantangan dihadapi sistem keuangan Islam, seperti pada aspek teoritis, operasional dan implementasi. Pada aspek teoritis, dibutuhkan pengembangan prinsip, filosofis dan fungsi sistem keuangan atas dasar pembagian keuntungan dan kerugian (profit-loss sharing). Pada sisi operasional, dibutuhkan perhatian

terhadap inovasi, intermediasi, disiplin dan pengendalian resiko, sementara pada sisi implementasi diperlukan aplikasi sistem yang harus disesuaikan dengan regulasi, dan kondisi perekonomian masyarakat saat ini. Pengaturan tata kelola perbankan syariah telah tertuang dalam Pasal 34 ayat 1-3 UU No. 21 Tahun 2008.

Hasil riset pengembangan pasar yang dilakukan oleh Bank Indonesia bersama tahun 2007 bersama MarkPlus.co yang menghasilkan pemetaan segmentasi konsumen bank syariah berdasarkan orientasi bank dibagi berdasarkan segmen pada gambar 1. berikut ini:

\footnotetext{
1) Jurnal ini merupakan bagian dari skripsi Fachruddin 'Aabid, NIM. 041211433009, yang diuji pada tanggal 9 Februari 2016
} 


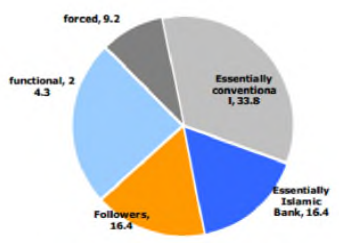

Hasil Survey MDSP tahun 2007

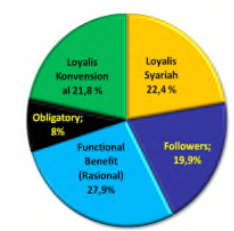

Hasil Survey MDSP tahun 2010
Sumber: Model Bisnis Perbankan Syariah BI, 2012:71

\section{Gambar 1.}

\section{Segmen Nasabah Bank Syariah}

Berdasarkan jumlah presentasi konsumen persegmen pada gambar 1 , maka yang terbesar adalah masih konsumen essentially conventional, atau sebesar 33.8\% dan menurun pada 2010 menjadi $21.8 \%$. Potensi konsumen perbankan syariah dari segmen sharia loyalis dan followers adalah masingmasing $16.4 \%$ (total $32.8 \%$ dari total segmen), sedangkan yang functional adalah 4.3\%. Pada tahun 2010 jumlah ini meningkat menjadi total $42.3 \%$ dengan kenaikan pada masing-masing segmen sharia loyalis dan followers. Sedangkan sebagai tambahan, survei perilaku investasi dari kalangan konsumen perbankan syariah yang dilakukan di Jawa, Sumatera dan Kalimantan menyebutkan bahwa dalam rangka memilih bank syariah, beberapa faktor menjadi perhatian yaitu kepatuhan syariah dari bank tersebut (100\%), kemudahan akses (53.5\%), kredibilitas bank tersebut (27.4\%) dan profesionalisme (14\%).

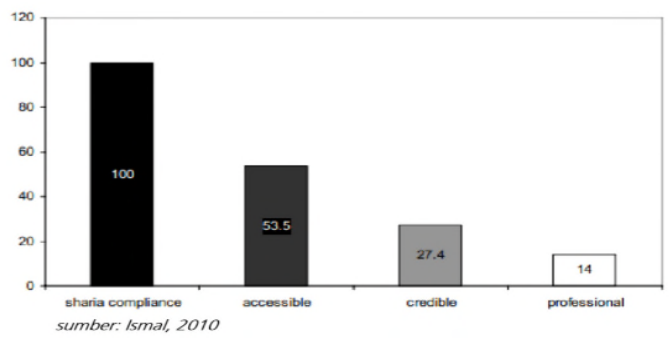

Gambar 2.

Kriteria Pemilihan Bank Syariah

Dari survei kriteria pada gambar 2. tersebut dapat diketahui bahwa bagi perbankan syariah Indonesia, sharia compliance merupakan suatu faktor yang tidak bisa ditawar lagi. Maka penting untuk dilakukan pengawasan fungsi kepatuhan syariah di industri keuangan syariah yang dapat dicerminkan melalui implementasi tata kelola syariah. Hal ini dilakukan sematamata untuk mengontrol operasional perbankan syariah agar tidak keluar dari koridornya, disiplin, dan langkah untuk meminimalisir resiko perbankan serta dapat membantu meningkatkan reputasi dan kepercayaan suatu industri kevangan syariah secara umum.

Berdasarkan paparan latar belakang, rumusan masalah dalam penelitian ini adalah: Bagaimana proses implementasi good sharia governance (GSG) di PT. BPRS Jabal Nur dalam menjamin aspek kepatuhan syariah (sharia compliance)?

Berdasarkan pada rumusan masalah, penelitian ini bertujuan untuk menemukan serta menganalisa proses implementasi GSG terhadap jaminan aspek kepatuhan syariah di PT. BPRS Jabal Nur.

\section{LANDASAN TEORI}

Menurut Sudarsono (2007:27), pada umumnya yang dimaksud bank syariah 
'Aabid, et al/Jurnal Ekonomi Syariah Teori dan Terapan Vol. 3 No. 5 Mei 2016: 346-358; PENERAPAN TATA KELOLA SYARIAH LEMBAGA KEUANGAN ISLAM (Studi Kasus Pada PT. BPRS Jabal Nur Surabaya)

adalah lembaga kevangan yang usaha pokoknya memberikan kredit dan jasajasa lain dalam lalu lintas pembayaran serta peredaran vang yang beroperasi disesuaikan dengan prinsip-prinsip syariah. Bank Umum Syariah (BUS) yang dalam kegiatannya memberikan jasa lalu lintas pembayaran, sedangkan BPRS adalah bank yang melaksanakan kegiatan usaha berdasarkan prinsip syariah yang dalam kegiatannya tidak memberikan jasa dalam lalu lintas pembayaran seperti layanan giro (Rivai, 2010: 32).

Sharia governance adalah hal yang fundamental bagi seluruh lembaga kevangan islam dan tidak kalah penting daripada corporate governance pada setiap institusi. Karena GSG juga bagian dari GCG yang dikhususkan untuk lembaga keuangan Islam. Hal tersebut adalah suatu mekanisme untuk dapat mengukur tingkat kepatuhan syariah setiap lembaga keuangan Islam. Peran sharia governance untuk memastikan kepercayaan stakeholders terhadap suatu lembaga keuangan Islam. Selain itu, sejarah telah menunjukkan bahwa peningkatan aspek sharia compliance dapat membantu percepatan pertumbuhan industri keuangan Islam (Haqqi, 2014:118).

Pembahasan dalam konteks industri perbankan, tata kelola perusahaan yang baik adalah sesuatu tata kelola Bank yang menerapkan prinsip-prinsip keterbukaan (transparency), akuntabilitas (accountability), pertanggungjawaban (responsibility), independensi (independency), dan keadilan (fairness). Corporate governance pada konvensional dan syariah memiliki banyak perbedaan sudut pandang (Choudury dan Hoque, 2006). Hal yang paling pokok adalah peletakan ideologi tauhid dalam perspektif syariah terhadap ideologi rasionalisme dalam perspektif konvensional. Selain itu, tujuan dari sebuah usaha dalam perspektif konvensional pada umumnya adalah maksimalisasi keuntungan, sementara pada perspektif syariah lebih bertujuan pada kesejahteraan umat. Penjelasan terhadap perbedaan cara pandang dirangkum

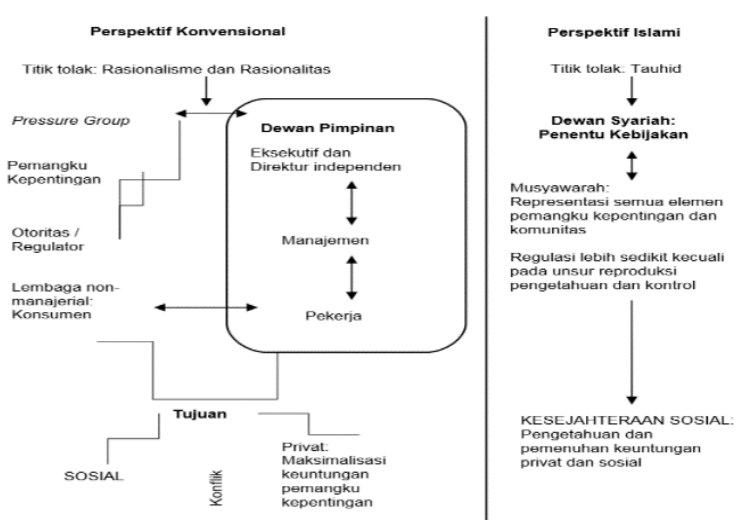

pada gambar 3. berikut ini:

Sumber: Choudury dan Hoque (2006)

Gambar 3.

Perbedaan Perspektif Tata Kelola Syariah dan Konvensional

Sudah ada banyak upaya untuk standarisasi dari praktik yang diikuti oleh berbagai lembaga keuangan Islam ini. Pedoman atau standar sharia governance yang berlaku global saat ini adalah standar yang diterbitkan oleh AAOIFI, IFSB, dan BNM. 
'Aabid, et al/Jurnal Ekonomi Syariah Teori dan Terapan Vol. 3 No. 5 Mei 2016: 346-358; PENERAPAN TATA KELOLA SYARIAH LEMBAGA KEUANGAN ISLAM (Studi Kasus Pada PT. BPRS Jabal Nur Surabaya)

Pada dasarnya, ada 7 standar dalam standar tata kelola untuk lembaga kevangan Islam yang dikeluarkan oleh AAOIFI adalah sebagai berikut:

(1) Sharia Supervisory Board: Appointment, Composition and Report,

(2) Sharia Review,

(3) Internal Sharia Review,

(4) Audit \& Governance Committee for Islamic Financial Institutions,

(5) Independence of Sharia Supervisory Boards,

(6) Statement on Governance Principles for Islamic Financial Institutions,

(7) Corporate Social Responsibility Conduct and Disclosure for Islamic Financial Institutions.

Menurut AAOIFI, Dewan Pengawas Syariah (DPS) didefinisikan sebagai:

"An independent body of specialized jurist in figh al muamalah (Islamic commercial jurisprudence). However, the Sharia supervisory board may include a member other than those specialized in fiqh mua'malat, but should be an expert in the field of Islamic Financial Institutions (IFls) with the knowledge of fiqh mua'malat."

Mengenai penunjukan anggota DPS, harus ditunjuk oleh para pemegang saham dalam Rapat Umum tahunan (RUPS) atas rekomendasi Dewan Direksi. Pemegang saham juga dapat mengotorisasi Dewan Direksi untuk memperbaiki remunerasi DPS pada Lembaga Keuangan Syariah (LKS).

Menurut AAOIFI, sharia review atau tinjauan syariah didefinisikan sebagai:
"An examination of the extent of an IFl's compliance in all its activities. The examination includes the contracts, agreements, policies, products, transactions, memorandum and articles of association, financial statements, reports (especially internal audit and central bank inspection), circulars, etc."

Tujuan dari mekanisme ini adalah untuk memastikan bahwa kegiatan yang dilakukan oleh LKS tidak melanggar syariat. Anggota DPS bertanggung jawab untuk membentuk dan memberikan pendapat mereka tentang kesesuaian LKS terhadap prinsip-prinsip syariah. Namun, tanggung jawab untuk kepatuhan adalah masih ada pada lingkup manajemen.

Selain sharia review, AAOIFI menyarankan kepada LKS untuk menerapkan secara praktis internal sharia review atau tinjauan internal syariah. Tujuannya adalah untuk memastikan bahwa manajemen LKS melakukan tanggung-jawab mereka dalam kaitannya dengan pelaksanaan peraturan dan prinsip-prinsip syariah yang ditetapkan oleh DPS. Internal sharia review juga dapat disebut sebagai implementasi sharia review. Penerapan internal sharia review diperlukan karena termasuk bagian integral dari manajemen LKS. Internal sharia review dapat dilakukan oleh Departemen Internal Audit atau Departemen Pengendalian Internal.

El Tiby (2011:165-168) menjelaskan bahwa IFSB mengelvarkan standar prinsip pengelolaan tentang kepatuhan sistem tata kelola syariah untuk membantu 
'Aabid, et al/Jurnal Ekonomi Syariah Teori dan Terapan Vol. 3 No. 5 Mei 2016: 346-358; PENERAPAN TATA KELOLA SYARIAH LEMBAGA KEUANGAN ISLAM (Studi Kasus Pada PT. BPRS Jabal Nur Surabaya)

kontrol tata kelola yang sudah ada dan fungsi pemenuhan dalam Lembaga Jasa Kevangan Islam (LJKI) atau Institutions Islamic Financial Servicer (IIFS). IFSB (2009b) mendefinisikan sistem tata kelola syariah (sharia governance system) sebagai berikut:

"Seperangkat peraturan institusional dan organisasional yang mana tiap LJKI menjamin adanya pengawasan yang efektif dan independen terhadap kepatuhan syariah akan setiap struktur dan proses di bawah ini:

a. Penerbitan pernyataan syariah yang relevan tentang LJKI

b. Penyebaran informasi tentang pernyataan syariah ke anggota LJKI

c. Pemeriksaan atau audit internal kepatuhan syariah

d. Pemerikasan atau audit tahunan kepatuhan."

Shariah Governance Framework (SGF) adalah pedoman yang berlaku untuk lembaga keuangan Islam yang dikeluarkan oleh Bank Negara Malaysia (BNM) pada tahun 2010. Framework ini berfungsi untuk memastikan lingkungan operasi lembaga keuangan Islam yang sesuai dengan prinsip-prinsip syariah. Islamic Banking and Takaful Department of Bank Negara Malaysia (2010:4-5) menjelaskan bahwa kerangka ini terbagi ke dalam enam bagian, yaitu:

(i) Persyaratan umum,

(ii) Perngawasan, akuntabilitas, dan tanggung jawab,

(iii) Independensi,

(iv) Kompetensi,

(v) Kerahasiaan dan konsistensi,

(vi) Kepatuhan syariah dan fungsi penelitian.
Bagian terpenting dari tata kelola syariah adalah proses. Proses tata kelola syariah merepresentasikan fungsi instrumental dewan syariah sebagai bagian dari struktur badan internal tata kelola suatu LKS. Hasan (2012:74-84) menjelaskan bahwa terdapat proses tata kelola syariah yang dalam hal ini meliputi (1) Penunjukkan DPS, (2) Komposisi DPS, (3) Kualifikasi DPS, (4) Proses Kepatuhan Syariah, (5) Koordinasi Syariah, (6) Tinjauan Kepatuhan Syariah, dan (7) Laporan Syariah.

Ada beberapa penelitian sebelumnya yang mendukung penelitian ini. Berikut ini merupakan salah satu penelitian sebelumnya yang membahas tema serupa yakni International Journal of Business and Social Science. Vol. 4 No. 15 yang berjudul Comparative Analysis on AAOIFI, IFSB, and BNM Sharia Governance Guidelines oleh Nawal Kasim dkk pada tahun 2010.

Hasil penelitiannya ialah semua pedoman tidak cukup komprehensif, seperti AAOIFI, IFSB dan BNM. Penulis menyarankan bahwa LKS harus memiliki satu pedoman standar sehingga akan mudah menjadi referensi untuk pelaku industri LKS, regulator, Penasihat Syariah dan investor.

Persamaannya ialah menggunakan standar atau pedoman AAOIFI, IFSB, dan BNM untuk landasan teori tata kelola syariah.

Perbedaannya ialah jurnal tersebut hanya berfokus pada perbandingan 
'Aabid, et al/Jurnal Ekonomi Syariah Teori dan Terapan Vol. 3 No. 5 Mei 2016: 346-358; PENERAPAN TATA KELOLA SYARIAH LEMBAGA KEUANGAN ISLAM (Studi Kasus Pada PT. BPRS Jabal Nur Surabaya)

standar tata kelola internasional, sedangkan peneliti juga membutuhkan regulasi seperti UU, PBI, SE BI, dan POJK sebagai dasar pembahasan tata kelola syariah di Indonesia

\section{METODE PENELITIAN}

Berdasarkan rumusan masalah yang telah ditentukan penulis, penulisan ini menggunakan pendekatan penelitian kualitatif deskriptif dengan metode studi kasus untuk menjawab pertanyaan pada rumusan masalah "Bagaimana proses implementasi Good Sharia Governance (GSG) di Bank Syariah dalam menjamin kemurnian dan kepatuhan syariah (Sharia Compliance)?". Menurut Yin (2009:2) pendekatan kualitatif adalah pendekatan dengan menggunakan data yang berupa kalimat tertulis atau lisan, peristiwaperistiwa, pengetahuan atau proyek studi yang bersifat deskriptif. Pendekatan kualitatif dengan metode deskriptif adalah mengkomunikasikan realitas yang ada dengan berdasarkan sudut pandang dari informan. Alasan peneliti menggunakan pendekatan penelitian kualitatif deskriptif adalah karena penelitian ini bertujuan untuk menguraikan analisis pada proses, bukan untuk menguji sebuah hipotesis atau pengaruh signifikansi. Manfaat strategi dari metode ini adalah untuk mendapatkan data yang lebih dalam, lebih lengkap, kredibel, dan bermakna sehingga tujuan penelitian dapat dicapai.
Ruang lingkup dalam penelitian ini fokus pada bagaimana proses implementasi Good Sharia Governance (GSG) di PT. BPRS Jabal Nur dalam menjamin aspek kepatuhan syariah berdasarkan standar serta regulasi yang berlaku.

Berdasarkan sumbernya terdapat dua jenis sumber data yang dapat dikumpulkan oleh peneliti untuk mendukung penelitian yang dilakukan, yaitu:

1. Data pertama adalah melalui sumber primer, yaitu data yang diperoleh peneliti secara langsung dari informan utama dengan cara menanyakan sesuatu atau yang disebut dengan wawancara.

2. Data yang kedua adalah melalui sumber sekunder, yaitu data yang berunsur non-manusia sebagai data pendukung penelitian, data yang dimaksud adalah data-data yang bersifat dokumen.

Unit Analisis dalam penelitian ini adalah serangkaian proses implementasi Good Sharia Governance (GSG) di PT. BPRS Jabal Nur.

Teknik pengumpulan data yang dapat digunakan dalam penelitian kualitatif diantaranya adalah observasi, partisipasi, studi dokumen dan wawancara (Yin, 2009:90). Pengumpulan data merupakan fase yang paling penting dalam penelitian karena hal tersebut berhubungan langsung dengan masalah yang diteliti dan nantinya yang akan diambil 
'Aabid, et al/Jurnal Ekonomi Syariah Teori dan Terapan Vol. 3 No. 5 Mei 2016: 346-358; PENERAPAN TATA KELOLA SYARIAH LEMBAGA KEUANGAN ISLAM (Studi Kasus Pada PT. BPRS Jabal Nur Surabaya)

kesimpulan. Penelitian ini menggunakan teknik pengumpulan data observasi, wawancara dan studi dokumen atau dokumentasi.

Validitas adalah derajat ketepatan yang terjadi antara data dengan daya yang dapat dilaporkan pada objek penelitian oleh peneliti. Data yang valid adalah data yang sama dengan data yang dilaporkan oleh peneliti berdasarkan keadaan yang benar-benar terjadi. Penelitian ini menggunakan teknik validasi triangulasi sumber dan teknik.

Setelah dilakukan pengumpulan data penelitian, maka data tersebut dianalisis untuk mendapatkan kesimpulan. Datadata yang diperoleh dari proses wawancara, observasi, dan studi dokumen kemudian di analisis dan diolah berdasarkan landasan teori dan literatur yang digunakan dalam penelitian ini. Analisis data dilakukan agar hasil yang diperoleh dapat dibaca dengan mudah dan dipahami. Teknik analisis yang digunakan dalam penelitian ini menggunakan teknik analisis data menurut Miles and Huberman dalam buku Sugiono (2014:91), yang menjelaskan ada tiga proses yaitu reduksi data, penyajian data, dan verifikasi atau menarik kesimpulan. Aktivitas dalam analisis data kualitatif dilakukan secara interaktif dan berlangsung secara terus menerus pada setiap tahapan penelitian sehingga sampai tuntas, dan datanya sampai jenuh.

\section{HASIL DAN PEMBAHASAN}

PT. BPRS Jabal Nur diresmikan oleh Deputi Gubenur Bank Indonesia Siti Fadjiyah, untuk dapat menjalankan operasinya sejak tanggal 26 Oktober 2007. Penetapan nama Jabal Nur adalah terinspirasi dari nama bukit di Arab Saudi yang sudah sangat dikenal oleh umat Islam di seluruh dunia termasuk umat Islam di Indonesia, baik karena cerita riwayat perjalanan maupun aktivitas Rasulullah SAW dalam pengembangan agama Islam.

Ditetapkan Kota Surabaya sebagai lokasi kantor BPRS Jabal Nur, dengan pertimbangan bahwa (a) Hampir $70 \%$ asset perbankan ada di kota Surabaya, dan ini menunjukkan, (b) Dana masyarakat Jawa Timur sebagian besar beredar di Kota Surabaya, (c) Belum banyaknya BPRS yang berdiri di Kota Surabaya. Segmen pasar yang dilayani adalah masyarakat kecil dengan usahausaha kecil dan mikro di Kota Surabaya khususnya dan di Jawa timur pada umumnya.

Ringkasan visi dan misi serta program produk dan ringkasan informan penelitian di BPRS Jabal Nur dapat dijelaskan pada tabel 1. dan tabel 2. berikut ini:

Tabel 1.

Ringkasan Visi Misi dan Program PT. BPRS Jabal Nur

\begin{tabular}{|c|l|l|}
\hline No & \multicolumn{1}{|c|}{ Visi } & \multicolumn{1}{|c|}{ Misi } \\
\hline 1 & $\begin{array}{l}\text { Sebagai } \\
\text { Kholifah }\end{array}$ & $\begin{array}{l}\text { Sebagai penyebar rahmat yang diberikan Allah kepada } \\
\text { seluruh alam. }\end{array}$ \\
\hline $\mathbf{2}$ & $\begin{array}{l}\text { Corporate } \\
\text { Culture }\end{array}$ & $\begin{array}{l}\text { Melakukan pelayanan perbankan sistim syariah terbaik } \\
\text { berlandaskan imtaq dan ibadah }\end{array}$ \\
\cline { 3 - 4 } & $\begin{array}{l}\text { Mengutamakan pelayanan pada pengusaha mikro, kecil } \\
\text { dan menengah untuk menunjang perkembangan ekonomi } \\
\text { masyarakat }\end{array}$ \\
\cline { 3 - 4 } & $\begin{array}{l}\text { Memberikan pelayanan terbaik dan prima kepada nasabah } \\
\text { dengan melaksanakan GCG berlandaskan imtaq. }\end{array}$ \\
\cline { 3 - 4 } & $\begin{array}{l}\text { Memberikan keuntungan dan manfaat yang optimal } \\
\text { kepada nasabah dan stakeholders. }\end{array}$ \\
\hline \multirow{2}{*}{ PROGRAM } & $\begin{array}{l}\text { Penggalangan simpanan atau tabungan untuk usaha yang } \\
\text { berjenis mikro ataupun makro melalui fasiltas pembiayaan } \\
\text { berupa modal usaha. }\end{array}$ \\
\hline
\end{tabular}

Sumber: Hasil Penelitian, 2015 (diolah) 
'Aabid, et al/Jurnal Ekonomi Syariah Teori dan Terapan Vol. 3 No. 5 Mei 2016: 346-358; PENERAPAN TATA KELOLA SYARIAH LEMBAGA KEUANGAN ISLAM (Studi Kasus Pada PT. BPRS Jabal Nur Surabaya)

Tabel 2.

Ringkasan Singkat Daftar Informan PT. BPRS Jabal Nur

\begin{tabular}{|l|c|c|c|c|c|c|}
\hline \multirow{2}{*}{ Keterangan } & \multicolumn{7}{|c|}{ Informan } \\
\cline { 2 - 7 } & $\mathbf{l}$ & $\mathbf{2}$ & $\mathbf{3}$ & $\mathbf{4}$ & $\mathbf{5}$ & $\mathbf{6}$ (ext) \\
\hline Jabatan & Direktur & IC & Komisaris & Ketua DPS & Kabag & Dirut \\
\hline Pendidikan & D3 & S1 & S1 & S2 & S1 & S2 \\
\hline $\begin{array}{l}\text { Masa Kerja } \\
\text { (tahun) }\end{array}$ & 8 & 1 & 1,5 & 8 & 5 & 7 \\
\hline
\end{tabular}

Sumber: Hasil Penelitian, 2015 (diolah)

\section{Pembahasan}

Mekanisme penunjukan Dewan Pengawas Syariah (DPS) yang terjadi pada PT. Bank Pembiayaan Rakyat Syariah Jabal Nur ialah dimulai dari usulan nama-nama oleh peserta RUPS Luar Biasa. Jika disetujui maka hasil usulan tersebut dibawa ke DSN-MUI untuk dimintakan rekomendasi, bersamaan dengan itu pula dilakukan pengajuan ke OJK. Setelah mendapatkan surat rekomendasi dari DSN-MUI yang disampaikan oleh pihak direksi BPRS, maka OJK melakukan penilaian-penilaian terhadap nama calon DPS tersebut. Penilaian-penilaian yang dimaksud adalah penilaian persyaratan administrasi seperti dokumen sertifikasi pendidikan dasar syariah, pengawasan, hingga penilaian mengenai track record keuangan seperti histori kredit. Selanjutnya terdapat fit and proper test sebagai tahap akhir sebelum OJK memberikan keputusan beserta pengesahannya.

Inisiator yang berhak mencalonkan nama-nama DPS ialah seluruh peserta pada RUPS Luar Biasa. Peserta RUPS tersebut meliputi pemegang saham, pemegang saham pengendali, serta pengurus yang terdiri dari direksi, komisaris, dan DPS. Seringkali pemegang saham pengendali dapat menentukan arah pembahasan. Direksi bisa mengusulkan melalui komisaris selaku perwakilan dari pemegang saham, tetapi tetap keputusan tertinggi ada di RUPS. Pertimbangan yang digunakan oleh inisiator ialah aspek kompetensi di bidang pengawasan atau pemeriksaan, aspek ketokohan publik serta acceptable bagi direksi atau dapat diterima dan dapat bekerja sama di semua lini manajemen. Aspek acceptable bagi direksi sesuai dengan AAOIFI yang menyatakan bahwa, DPS ditunjuk oleh pemegang saham di RUPS dengan rekomendasi Dewan Direksi. Kualifikasi auditor secara umum di PT. Bank Pembiayaan Rakyat Syariah adalah sebagai berikut.

1. Memahami segala aturan yang berlaku (UU, Fatwa, SOP, SE, SK),

2. Memiliki integritas,

3. Menaati kode etik dan independen,

4. Memiliki mental kuat dan stabil,

5. Memiliki pengetahuan luas tentang analisa dan interpretasi.

Bagian yang sangat menarik untuk dibahas lebih mendalam ialah adanya aspek ketokohan publik sebagai salah satu aspek pertimbangan inisiator dalam memberikan calon nama-nama DPS dalam RUPS. Aspek ketokohan publik dari DPS dapat menjadi bagian dari pertimbangan inisiator dalam proses pemilihan calon nama-nama DPS di RUPS 
'Aabid, et al/Jurnal Ekonomi Syariah Teori dan Terapan Vol. 3 No. 5 Mei 2016: 346-358; PENERAPAN TATA KELOLA SYARIAH LEMBAGA KEUANGAN ISLAM (Studi Kasus Pada PT. BPRS Jabal Nur Surabaya)

karena menurut ibu Pram selaku direktur menyatakan bahwa, aspek ketokohan yang dimiliki DPS dapat dijadikan sebagai figur positif untuk bisa menambah kepercayaan publik kepada bank syariah.

Proses kepatuhan syariah di PT. Bank Pembiayaan Rakyat Syariah (BPRS) Jabal Nur ditunjang dari dua aspek yang saling berkesinambungan, yakni pendidikan dan pengawasan. Selain adanya 2 aspek tersebut, terdapat pula sosialisasi SOP dan program edukasi agar proses kepatuhan syariah dapat berjalan dengan baik.

Standar tata kelola dan kepatuhan syariah yang diterapkan di PT. BPRS Jabal Nur adalah berdasarkan pada Peraturan Bank Indonesia (PBI), Peraturan Otoritas Jasa Keuangan (POJK), Fatwa DSN, dan Undang-Undang yang berlaku.

Koordinasi pengawasan pada PT. BPRS Jabal Nur bertujuan untuk mengontrol operasional perbankan syariah agar tidak kelvar dari koridornya. Selain itu, adanya pelaksanaan koordinasi pengawasan akan membuat manajemen risiko bank dapat berjalan dengan efektif dan sebagai langkah untuk meminimalisir risiko perbankan syariah yakni sharia compliance risk, serta dapat membantu meningkatkan reputasi dan kepercayaan suatu industri keuangan syariah secara umum.

Adapun serangkaian proses pengawasan di PT. Bank Pembiayaan Rakyat Syariah Jabal Nur ada 4 tahapan yang terdiri dari:
1. WASKAT, pengawasan melekat pada sistem berupa SOP, SK, $\mathrm{SE}$, dan segala ketentuan prosedur yang berlaku.

2. PAL, pengawasan atasan langsung oleh setiap pimpinan di masing-masing lini.

3. Audit Internal, audit yang dilakukan oleh fungsi pengawasan PT. BPRS Jabal Nur yakni oleh DPS, komisaris, dan IC.

4. Audit Eksternal, audit yang dilakukan oleh pihak eksternal seperti KAP dan OJK.

Pola koordinasi DPS dan Dewan Komisaris adalah bagian dari fungsi pengawasan, sedangkan antara DPS dan IC ialah sama-sama memiliki fungsi pemeriksaan. Koordinasi fungsi pemeriksaan terdapat pada aspek sharia review dan internal sharia review. Dewan Pengawas Syariah bertanggung jawab untuk membentuk dan memberikan pendapat mereka tentang kesesuaian LKS terhadap prinsip-prinsip syariah. Kemudian untuk memastikan bahwa manajemen LKS melakukan tanggung-jawab mereka dalam kaitannya dengan pelaksanaan peraturan dan prinsip-prinsip syariah yang ditetapkan oleh DPS, maka diperlukan internal sharia review yang dapat juga disebut sebagai implementasi sharia review.

Penilaian tata kelola syariah pada PT. Bank Pembiayaan Rakyat Syariah (BPRS) Jabal Nur terhadap jaminan kepatuhan 
syariah ialah sudah berjalan cukup baik. Hanya saja penilaian tersebut didasarkan pada hasil pengawasan auditor (DPS, komisaris, dan IC), kelengkapan fungsi struktur organisasi, dan tingkat pemahaman pegawai terhadap peraturan syariah. Penialaian yang telah diungkapkan oleh jajaran pengurus belum diungkapkan secara penuh (full disclosure) dikarenakan seluruh dokumen hasil audit bersifat terkendali atau rahasia. Hanya ada piagam penghargaan dan laporan publikasi keuangan triwulan yang dipublikasikan di masing-masing kantor BPRS Jabal Nur.

PT. Bank Pembiayaan Rakyat Syariah Jabal Nur memiliki cara sendiri untuk mengkomunikasikan tata kelola syariah yang baik dalam rangka menjamin aspek kepatuhan syariah, sesuai tabel 3. berikut ini.

Tabel 3.
Ringkasan Bentuk Komunikasi Tata Kelola dan Kepatuhan Syariah PT. BPRS Jabal Nur

\begin{tabular}{|c|c|c|c|c|}
\hline \multirow{2}{*}{ No. } & \multirow{2}{*}{ Sumber } & \multicolumn{3}{|c|}{ Bentuk Komunikasi Kepada } \\
\hline & & Pemegang Saham & Regulator & Publik \\
\hline 1 & Bapak Amin & & $\begin{array}{l}\text { Laporan DPS } \\
\text { setiap semester }\end{array}$ & $\begin{array}{l}\text { 1. Laporan Publikasi } \\
\text { Keuangan }\end{array}$ \\
\hline 2 & Ibu Isnani & $\begin{array}{l}\text { Penyampaian } \\
\text { Laporan Hasil } \\
\text { Rencana Kerja } \\
\text { (RKA) Tahunan }\end{array}$ & $\begin{array}{l}\text { Laporan } \\
\text { Pelaksanaan } \\
\text { RKA Dewan } \\
\text { Komisaris } \\
\text { setiap semester }\end{array}$ & $\begin{array}{l}\text { 2. Piagam Penghargaan } \\
\text { 3. Pelayanan Informasi } \\
\text { Terpadu oleh semua } \\
\text { lini manajemen } \\
\text { beserta tokoh agama }\end{array}$ \\
\hline 3 & Bapak Donny & melalui komisaris & Laporan RKA & $\begin{array}{l}\text { atau Ulama } \\
\text { 4. Edukasi ke Publik }\end{array}$ \\
\hline 4 & Ibu Pram & pemegang saham & Tahunan & $\begin{array}{l}\text { bekerjasama dengan } \\
\text { OJK }\end{array}$ \\
\hline
\end{tabular}

Berdasarkan hasil pembahasan di atas, maka proses implementasi GSG di PT. Bank Pembiayaan Rakyat Syariah Jabal Nur dapat dirangkum dan diuraikan pada gambar 4. berikut ini.

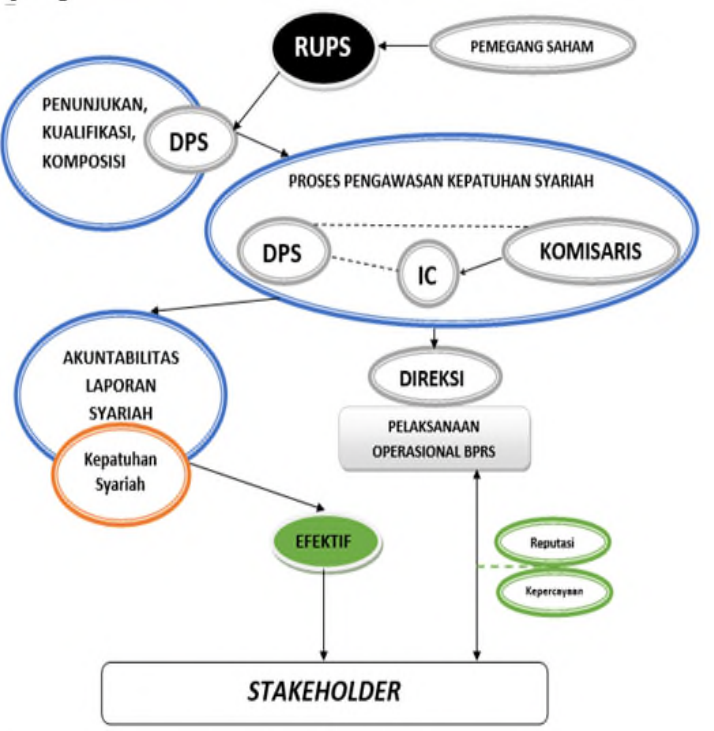

Sumber: Hasil Penelitian, 2016 (diolah)

Gambar 4.

Skema Proses Tata Kelola Syariah PT. BPRS Jabal Nur

Dalam penelitian ini peneliti memiliki beberapa keterbatasan penelitian dalam hal perolehan data secara lengkap dan mendalam. Hal itu dikarenakan terdapat beberapa data yang memang dirahasiakan dan hanya diketahui oleh pihak PT. Bank Pembiayaan Rakyat Syariah Jabal Nur. Contohnya adalah Standard Operating Procedure (SOP), laporan hasil audit internal oleh IC, dan laporan syariah yang diterbitkan oleh DPS PT. BPRS Jabal Nur.

\section{SIMPULAN}

Berdasarkan hasil penelitian yang dilakukan dapat disimpulkan bahwa proses implementasi GSG di PT. Bank Pembiayaan Rakyat Syariah (BPRS) Jabal Nur adalah sebagai berikut:

1. Proses penunjukan DPS di PT. BPRS Jabal Nur diawali dari usulan nama-nama oleh inisiator dari peserta RUPS Luar Biasa dengan 
pertimbangan aspek kompetensi di bidang pemeriksaan, aspek ketokohan publik serta acceptable bagi direksi atau dapat diterima serta bekerja sama di semua lini manajemen.

2. Jumlah DPS yang ada saat ini berjumlah 2, terdiri dari ketua dan anggota.

3. Kualifikasi DPS sudah sesuai dengan PBI No. 11/3/PBI/2009 Pasal 34 ayat 2, yakni integritas, kompetensi, dan reputasi keuangan.

4. Proses koordinasi dan pengawasan di PT. BPRS Jabal Nur dilakukan oleh seluruh lini manajemen. Dimulai dari WASKAT, PAL, dan audit internal oleh fungsi pengawasan dan pemeriksaan antara 3 pihak yakni DPS sebagai auditor sharia review dan komisaris beserta IC sebagai auditor internal sharia review, terakhir adalah audit eksternal oleh KAP dan OJK.

5. Bukti nyata adanya koordinasi antar pengurus terdapat pada exit meeting yang di dalamnya terdapat tinjauan segala aspek pengawasan dan pemeriksaan operasional maupun aspek syariah bersama dengan direksi beserta jajaran manajemen terkait.

6. Hasil pengawasan kepatuhan syariah belum diungkapkan secara penuh (full disclosure) kepada stakeholder sebagai bentuk akuntabilitas dan transparansi PT. BPRS Jabal Nur, karena seluruh dokumen hasil audit atau pemeriksaan DPS maupun IC bersifat terkendali atau rahasia.

7. Proses pelaporan dan akuntabilitas yang ada di PT. BPRS Jabal Nur adalah dilakukan dengan cara mempublikasikan laporan keuangan secara periodik di masing-masing kantor, publikasi piagam penghargaan, memberikan pelayanan informasi terpadu terkait aspek syariah kepada nasabah oleh semua lini manajemen beserta tokoh agama atau ulama, dan menjalankan program edukasi kepada publik yang bekerja sama dengan OJK.

Saran yang direkomendasikan setelah melakukan penelitian ini adalah sebagai berikut:

1. Bagi Institusi Perbankan Syariah

a. Penelitian ini diharapkan bisa memberikan masukan dan pertimbangan bagi perbankan syariah untuk lebih meningkatkan peran pengurus, khususnya dalam bidang pengawasan, agar kualitas tata kelola syariah dapat semakin meningkat dan terjaminnya prinsip kepatuhan syariah.

b. Sekiranya opini DPS dapat dipublikasikan baik secara langsung di kantor maupun 
'Aabid, et al/Jurnal Ekonomi Syariah Teori dan Terapan Vol. 3 No. 5 Mei 2016: 346-358; PENERAPAN TATA KELOLA SYARIAH LEMBAGA KEUANGAN ISLAM (Studi Kasus Pada PT. BPRS Jabal Nur Surabaya)

tidak langsung melalui laporan tahunan (annual report) yang diunggah pada website perusahaan perbankan syariah. Hal itu diwujudkan dalam rangka meningkatkan tingkat akuntabilitas dan transparansi bank syariah terhadap jaminan kepatuhan syariah kepada publik.

2. Bagi Peneliti Selanjutnya

a. Ada baiknya peneliti selanjutnya juga dapat lebih mendalami faktor penerapan tata kelola syariah, terlebih dari aspek ketokohan publik yang turut serta dijadikan pertimbangan oleh inisiator dalam proses penunjukan calon DPS di RUPS Luas Biasa.

\section{DAFTAR PUSTAKA}

AAOIFI. 2005. Governance Standards for IFIs, No 1-3. Bahrain: AAOIFI.

Bank Indonesia. 2008. Surat Edaran Bank Indonesia (SE) No. 12/13/DPbs tentang Pelaksanaan Good Corporate Governance bagi Bank Umum Syariah (BUS) dan Unit Usaha Syariah (UUS).

Bank Indonesia. 2004. Peraturan Bank Indonesia (PBI) No. 6/17/PBI/2004 tentang Bank Perkreditan Rakyat Berdasarkan Prinsip Syariah.
2009. Peraturan Bank Indonesia (PBI) No. 11/3/PBI/2009 tentang Bank Umum Syariah (BUS). . 2009. Peraturan Bank Indonesia (PBI) No. 11/33/PBI/2009 tentang Pelaksanaan Good Corporate Governance bagi Bank Umum Syariah (BUS) dan Unit Usaha Syariah (UUS) . 2011. Peraturan Bank Indonesia (PBI) No. 13/2/PBI/2011 tentang Pelaksanaan Fungsi Kepatuhan Bank Umum, Tanggal 12 Januari 2011.

Bank Negara Malaysia. 2010. Shari'ah Governance Framework for Islamic Financial Institutions. Kuala Lumpur: Bank Negara Malaysia.

Coudhury dan Hoque. 2006. Corporate Governance in Islamic Perspective. Corporate Governance 6(2): 116-128. Lihat juga, Ekayadi dan Rahmadi, 2010 , h. 4-5.

Departemen Perbankan Syariah BI. 2012. Kajian Model Bisnis Perbankan Syariah. Jakarta: Bank Indonesia.

El Tiby, Amr Mohamed. 2011. Islamic Finance: How to Manage Risk and Improve Profitability. New Jersey USA: John Wiley and Sons, Inc.

Hasan, Zulkifli. 2012. Shari'ah Governance in Islamic Banks Ch-3. Edinburgh: Edinburg Press Ltd.

Haqqi, Abdurrahman RA. 2014. Shariah Governance In Islamic Financial Institution: An Appraisal. Brunei Darussalam: Jurnal US-CHINA LAW REVIEW SHARIA GOVERNANCE, Vol. 11. 
'Aabid, et al/Jurnal Ekonomi Syariah Teori dan Terapan Vol. 3 No. 5 Mei 2016: 346-358; PENERAPAN TATA KELOLA SYARIAH LEMBAGA KEUANGAN ISLAM (Studi Kasus Pada PT. BPRS Jabal Nur Surabaya)

llyas, Nasirwan. 2006. Seputar IsU Corporate Governance dalam Bank Syariah, Buletin Hukum Perbankan dan Kebanksentralan. Jakarta: www.bi.go.id, tanggal akses 15 Oktober 2015

labal, Zamir dan Abbas Mirakhor. 2008. Pengantar Kevangan Islam: Teori dan Praktek, terj. Oleh A.K. Anwar. Jakarta: Prenada Media Group.

Islamic Financial Service Board (IFSB). 2009. Guiding Principles on Shariah Governance Systems for Institutions Offering Islamic Financial Services. Kuala Lumpur: IFSB

Lewis, K. Mervyn dan Algaoud, L.M. 2001. Perbankan Syariah Prinsip Praktek dan Prospek. Jakarta: Serambi IImu Semesta. Otoritas Jasa Keuangan (OJK), 2015. Peraturan Otoritas Jasa Kevangan (POJK) No. 4/POJK.03/2015 tentang Penerapan Tata Kelola Bagi Bank Perkreditan Rakyat.

Rivai, Veitthzal. 2010. Islamic Banking. Sistem Bank Islam Bukan Hanya Solusi Menghadapi Krisis Namun Solusi dalam Menghadapi Berbagai Persoalan Perbankan dan Ekonomi Global. Jakarta: Bumi Aksara.

Sudarsono, Heri. 2007. Bank dan Lembaga Kevangan Syariah, Deskripsi dan Ilustrasi. Yogyakarta: Ekonisia.

Sugiono. 2014. Memahami Penelitian Kualitatif. Bandung: Alfabeta.

Undang Undang Republik Indonesia No.21 Tahun 2008 Tentang Perbankan Syariah.
Yin, Robert K. 2009. Studi Kasus: Desain dan Metode. Jakarta: PT.Raja Grafindo Persada. 